\title{
Report of new cases of Trypanosoma caninum in Brazil
}

\author{
Tatiana da Silva Fonseca de Oliveira ${ }^{[1]}$, Juliana Helena Silva Barros ${ }^{[2]}$, \\ Taliha Dias Perez ${ }^{[3]}$, Fabiano Borges Figueiredo ${ }^{[4]}$, \\ Artur Augusto Velho Mendes Júnior ${ }^{[4]}$ and Maria de Fátima Madeira ${ }^{[1]}$
}

[1]. Laboratório de Pesquisa Clínica e Vigilância em Leishmanioses, Instituto Nacional de Infectologia Evandro Chagas, Fundação Oswaldo Cruz, Rio de Janeiro, Brasil. [2]. Laboratório de Biologia de Tripanosomatídeos, Instituto Oswaldo Cruz, Fundação Oswaldo Cruz, Rio de Janeiro, Brasil. [3]. Laboratório de Doenças Parasitárias, Instituto Oswaldo Cruz, Fundação Oswaldo Cruz, Rio de Janeiro, Brasil. [4]. Laboratório de Pesquisa Clínica em Dermatozoonoses, Instituto Nacional de Infectologia Evandro Chagas, Fundação Oswaldo Cruz, Rio de Janeiro, Brasil.

\begin{abstract}
Introduction: Trypanosoma caninum is a protozoan species recently described in dogs, whose occurrence has been reported in areas of overlap with visceral leishmaniasis. Methods: Trypanosoma sp. were isolated from nine dogs and characterized by molecular methods. Results: PCR and sequencing confirmed the presence of T. caninum in all dogs, revealing two new areas of transmission: Barra Mansa and São João do Piauí. Conclusions: The nine new cases described, when added to those already published, account for 62 cases of natural infection by T. caninum and show the geographical spread of this species to new areas, where other trypanosomatids circulate.
\end{abstract}

Keywords: Trypanosoma caninum. São João do Piauí. Barra Mansa.

Domestic dogs are naturally infected with different species of trypanosomatids ${ }^{(1)(2)(3)(4)}$. These animals are of particular interest with regard to the transmission cycle of Leishmania chagasi and Trypanosoma cruzi, because they are considered reservoirs for both agents and enhancers of transmission in the peridomicile, and consequently a risk factor for the human population $^{(3)(4)}$. Trypanosoma caninum is the most recently described species of the Trypanosoma genus affecting $\operatorname{dogs}^{(5)}$, with 53 cases confirmed in different regions of Brazil ${ }^{(6)}$ prior to this present study. The species has unique biological characteristics, including its isolation exclusively from intact skin fragments ${ }^{(5)(7)}$ and the presence of aflagellate epimastigote forms in axenic cultures ${ }^{(8)}$. It appears to be nonpathogenic to dogs, in which the infection triggers a mild humoral immune response $^{(7)(9)}$. However, the presence of T. caninum in areas overlapping with those affected by canine visceral leishmaniasis (CVL) has been identified as a possible confounding factor for the accurate diagnosis of CVL. Thus, such overlap may have a negative impact on the control of this disease ${ }^{(6)}$. Culturebased testing has been an important tool for the diagnosis of T. caninum infection, although recent studies have demonstrated that polymerase chain reaction (PCR)-based tests that amplify specific regions of the $18 \mathrm{~S}$ ribosomal DNA (rDNA) gene may

Corresponding author: Dra. Tatiana da Silva Fonseca de Oliveira. Laboratório de Pesquisa Clínica e Vigilância em Leishmanioses/INI/FIOCRUZ. Av. Brasil 4365, Manguinhos, 21040-360 Rio de Janeiro, Brasil.

Phone/Fax: 5521 3865-9541

e-mail: tatiana.fonseca@ini.fiocruz.br

Received 11 December 2014

Accepted 25 February 2015 be a valuable additional tool for diagnosis, particularly in areas overlapping with those affected by Leishmania chagasi ${ }^{(10)}$.

Herein we report nine new cases of natural infection by T. caninum in dogs, in the States of Rio de Janeiro and Piauí. Dogs from areas endemic for Chagas disease in Piauí (municipality of São João do Piauí) and CVL-endemic areas in Rio de Janeiro (municipalities of Barra Mansa and Rio de Janeiro) were evaluated from March 2013 to December 2014.

For clinical examinations and the collection of biological samples including blood, intact skin fragments, lymph nodes, and bone marrow aspirates, dogs were sedated with an intramuscular injection of ketamine hydrochloride $(10 \mathrm{mg} / \mathrm{kg})$ and acepromazine $(0.2 \mathrm{mg} / \mathrm{kg})$. All samples were transferred to screw-cap tubes containing blood agar slants (Novy-MacNealNicolle) overlaid with $1.5 \mathrm{~mL}$ of Schneider's Drosophila medium (Sigma) supplemented with $10 \%$ fetal calf serum ${ }^{(5)}$. The cultureisolated strains were identified using nested PCR with specific oligonucleotides to amplify a partial region of the $18 \mathrm{~S}$ rDNA gene. Nucleotide sequences were analyzed as previously described ${ }^{(6)}$. Six months later, an active search for infected dogs was performed with the aim of re-isolating parasites from skin fragments in the same region where the previous isolations were performed.

Nine samples of Trypanosoma sp. were isolated from nine dogs and analyzed in this study. The parasites were isolated exclusively from intact skin fragments. The dogs ranged in age from 3-5 years, and all were deemed to be asymptomatic and in good general health. Seven animals were from the municipality of Rio de Janeiro, one from the municipality of Barra Mansa, and another from the municipality of São João do Piauí (Figure 1). All isolates were identified as T. caninum and exhibited 100\% homology with T. caninum sequences from previous studies ${ }^{(6)}$. 


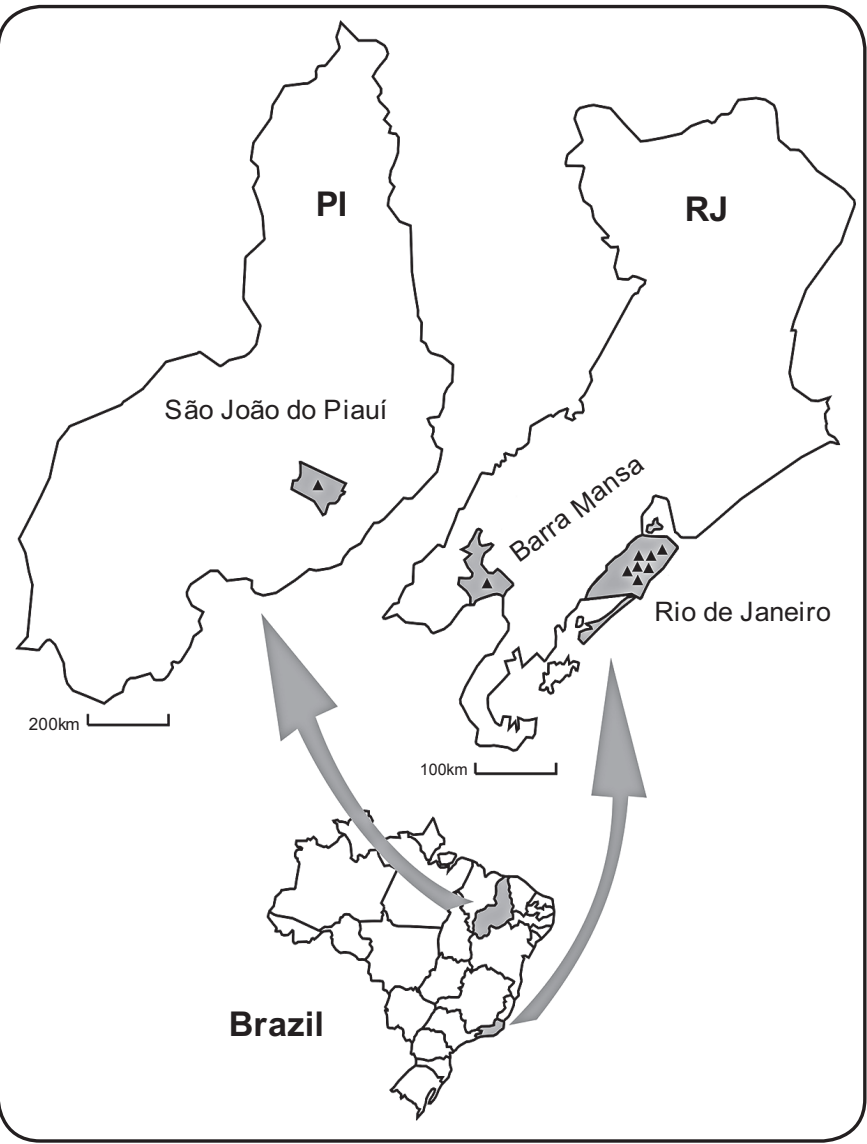

FIGURE 1 - Geographic locations of new cases of Trypanosoma caninum infection identified in the municipalities of São João do Piauí (PI), Barra Mansa, and Rio de Janeiro (RJ), in Brazil. PI: State of Piauí; RJ: State of Rio de Janeiro.
Six months after the initial isolation, four dogs previously diagnosed with $T$. caninum infection were found and reevaluated. T. caninum was only re-isolated in one of these dogs; the remaining three were negative. The data on animals and samples processed for diagnostic purposes are summarized in Table 1, and the distribution of cases of T. caninum infection by municipality is shown in Table 2 .

Trypanosoma caninum is a recently described species, and its occurrence has been reported in different States of Brazil ${ }^{(6)}$. Herein, we describe new cases of infection with this agent in two new transmission areas: Barra Mansa, in the State of Rio de Janeiro, and São João do Piauí, in the State of Piauí. All cases of $T$. caninum infection described to date have occurred in CVL-endemic areas, which highlights the need to assess the potential impact of the overlap of these species on CVL control $^{(6)}$. Seven cases described in this study originated in the Atlantic forest region in the municipality of Rio de Janeiro, on the eastern slope of the Pedra Branca massif, in the lowlands in the Jacarepaguá district, where cases of CVL have been described since the $1980 \mathrm{~s}^{(11)}$. On the other hand, in Barra Mansa, a municipality located in the southern region of the State of Rio de Janeiro, CVL was only recently diagnosed ${ }^{(12)}$ and one of the cases described in this study came from this region.

The present study reports, for the first time, a case of T. caninum infection in dogs in the municipality of São João do Piauí, which is an endemic area for $T$. $\mathrm{cruzi}^{(13)}$. In areas where the endemic diseases overlap, diagnosis using serological tests is unfeasible because their specificity may not be sufficient. The geographical dispersion of $T$. caninum into areas in which other trypanosomatids (i.e., Leishmania sp. and T. cruzi)

TABLE 1 - Diagnosis of Trypanosoma caninum in nine dogs determined by culture.

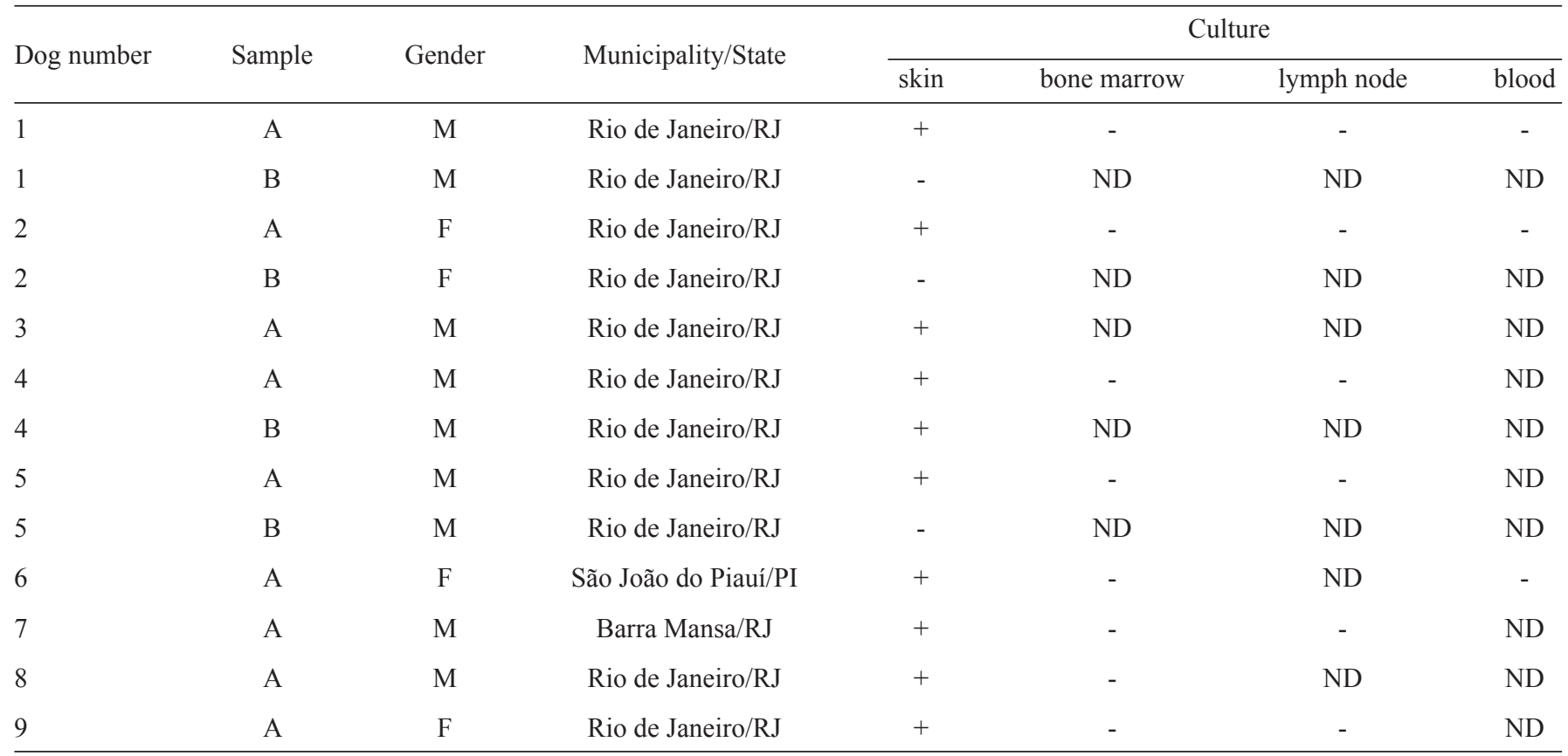

A: culture performed at baseline; B: culture performed after six months; M: male; F: female; +: positive culture; -: negative culture; ND: note done. 
TABLE 2 - Cases of Trypanosoma caninum infection (as percentages) by each municipality studied.

\begin{tabular}{lcc}
\hline Municipality (State) & Number & Pecentage \\
\hline Rio de Janeiro municipality (RJ) & 103 & 6.8 \\
Barra Mansa municipality (RJ) & 234 & 0.4 \\
São João do Piauí municipality (PI) & 80 & 1.25 \\
\hline
\end{tabular}

RJ: State of Rio de Janeiro; PI: State of Piauí.

circulate is a phenomenon that should be acknowledged and duly considered during diagnostic and epidemiological surveillance studies and interventions in these regions.

Our results are concordant with those previously published in the literature, in that to date T. caninum infection has only been found in intact skin fragments, as assessed by culture and PCR-based tests ${ }^{(7)}{ }^{(10)}$. Moreover, the absence of clinical signs in the dogs studied, and the re-isolation of T. caninum in only one of the four dogs re-evaluated months later support the hypotheses that infection with this agent is asymptomatic, and can be transient ${ }^{(7)}$. The nine new cases described in this study, when added to those already published ${ }^{(6)}$, constitute a total of 62 cases of natural T. caninum infection reported in six states of Brazil. The identification of these new isolates, in addition to improving the knowledge-base with regard to the geographical distribution of this species in Brazil, is a warning sign for the relevant epidemiological surveillance sectors in the municipalities of Barra Mansa and São João do Piauí.

\section{Ethical considerations}

This study was approved by the Ethics Committee on Animal Experimentation of the Oswaldo Cruz Foundation [Comissão de Ética no Uso de Animais do Instituto Oswaldo Cruz (CEUA/ FIOCRUZ), license LW-54/13].

\section{ACKNOWLEDGMENTS}

We thank Arlene BM Paula Ferreira de Almeida for her inestimable help with preparation of the map. We also thank Genomic Platform-DNA Sequencing (PDTIS-FIOCRUZ) for assistance with the sequencing of the samples in this study.

\section{CONFLICT OF INTEREST}

The authors declare that there is no conflict of interest.

\section{FINANCIAL SUPPORT}

The present study was partially financed by the National Council of Research Development [Conselho Nacional de Desenvolvimento Científico e Tecnológico (CNPq) - Program PAPES VI, process 407700/2012-9] and Research Support
Foundation of Rio de Janeiro State [Fundação de Amparo à Pesquisa do Estado do Rio de Janeiro (FAPERJ) - Program Young Scientist from our State, process E26/201.537/2014]. Maria de Fatima Madeira and Fabiano Borges Figueiredo hold a grant from $\mathrm{CNPq}$ for their productivity in the research.

\section{REFERENCES}

1. Franke CR, Greiner M, Mehlitz D. Investigations on naturally occurring Trypanosoma evansi infections in horses, cattle, dogs and capybaras (Hydrochaeris hydrochaeris) in Pantanal de Poconé (Mato Grosso, Brazil). Acta Trop 1994; 58:159-169.

2. Pifano F, Penãlver LM, Medina R, Dominguez E. La infección natural del perro por el Trypanosoma rangeli. Primeira comprobación de un reservorio extra humano vertebrado del protozoário en la naturaleza. Gac Med 1948; 56:130-134.

3. Dantas-Torres F. Canine leishmaniosis in South America. Parasit Vectors 2009; 2:1-8.

4. Enriquez GF, Bua J, Orozco MM, Wirth S, Schijman AG, Gürtler RE, et al. High levels of Trypanosoma cruzi DNA determined by qPCR and infectiousness to Triatoma infestans support dogs and cats are major sources of parasites for domestic transmission. Infect Genet Evol 2014; 25:36-43.

5. Madeira MF, Sousa MA, Barros JH, Figueiredo FB, Fagundes A, Schubach A, et al. Trypanosoma caninum n. sp. (Protozooa: Kinetoplastida) isolated from intact skin of a domestic dog (Canis familiaris) captured in Rio de Janeiro, Brazil. Parasitology 2009; 136:401-413.

6. Barros JHS, Almeida ABPF, Figueiredo FB, Sousa VRF, Fagundes A, Pinto AGS, et al. Occurrence of Trypanosoma caninum in areas overlapping with leishmaniasis in Brazil: what is the real impact of canine leishmaniasis control? Trans R Soc Trop Med Hyg 2012; 106:419-423.

7. Madeira MF, Almeida ABPF, Barros JHS, Oliveira TSF, Sousa VRF, Alves AS, et al. Trypanosoma caninum, a new parasite describe in dogs in Brazil: Aspects of natural infection. J Parasitol 2014; 100:231-234.

8. Barros JHS, Fonseca TS, Macedo-Silva R, Côrte-Real S, Toma HK, Madeira MF. Aflagelar epimastigote forms are found in axenic culture of Trypanosoma caninum. Acta Trop 2014; 137:147-151.

9. Alves AS, Mouta-Confort E, Figueiredo FB, Oliveira RVC, Schubach AO, Madeira MF. Evaluation of serological crossreactivity between canine visceral leishmaniasis and natural infection by Trypanosoma caninum. Res Vet Sci 2012; 93: 1329-1333.

10. Pinto AGS, Toma HK, Figueiredo FB, Madeira MF. Evaluation of $18 \mathrm{~S}$ rDNA PCR assay using skin fragments as a diagnostic test for Trypanosoma caninum. Vet Parasitol 2014; 205:343-346.

11. Marzochi MCA, Fagundes A, Andrade MV, Souza MB, Madeira MF, Mouta-Confort E, et al. Visceral leishmaniasis in Rio de Janeiro, Brazil: eco-epidemiological aspects and control. Rev Soc Bras Med Trop 2009; 42:570-580.

12. Mello CX, Figueiredo FB, Mendes-Júnior AAV, Furtado MC, Miranda LCF, Madeira MF. Outbreak of canine visceral leishmaniasis in Barra Mansa, State of Rio de Janeiro. Rev Soc Bras Med Trop 2014; 47:788-790.

13. Borges-Pereira J, Castro JAF, Silva AG, Zauza PL, Bulhões TP, Gonçalves $\mathrm{ME}$, et al. Soroprevalência da infecção chagásica no Estado do Piauí, 2002. Rev Soc Bras Med Trop 2006; 39:530-539. 